\title{
Microstructure and Wear Behavior of Spray Deposited Zn-30Al-1Cu Alloy
}

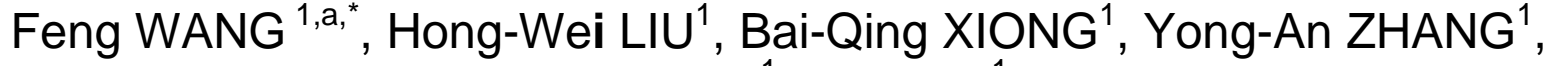 \\ Zhi-Hui LI ${ }^{1}, \mathrm{Xi}-\mathrm{Wu} \mathrm{LI}^{1}$ \\ ${ }^{1}$ State Key Laboratory for Nonferrous Metals and Process, General Research Institute for \\ Nonferrous Metals, Beijing 100088, China \\ awfbs@263.net \\ ${ }^{*}$ Corresponding author
}

Keywords: Microstructure, Wear behavior, Spray deposition, Zn-Al alloy.

\begin{abstract}
In this study, $\mathrm{Zn}-30 \mathrm{Al}-1 \mathrm{Cu}$ (wt.\%) alloy was prepared by the spray atomization and deposition technique. The microstructures of the spray-deposited and cast alloys were investigated by means of optical microscope, scanning electron microscope and X-ray diffraction. The wear resistance of the alloys was studied using a pin-on-disc machine under four loads, namely 20, 40, 60 and $80 \mathrm{~N}$. It can be seen that the microstructure of spray-deposited $\mathrm{Zn}-30 \mathrm{Al}-1 \mathrm{Cu}$ alloy is mainly composed of the $\mathrm{Zn} / \mathrm{Al}$ eutectoids, and the presence of $\varepsilon-\mathrm{CuZn} 4$ compounds in the conventional cast $\mathrm{Zn}-30 \mathrm{Al}-1 \mathrm{Cu}$ alloy was suppressed. The dry sliding wear test results indicate that spray deposited $\mathrm{Zn}-30 \mathrm{Al}-1 \mathrm{Cu}$ alloy exhibited an improved wear resistance at the entire applied load range in comparison to the cast one.
\end{abstract}

\section{Introduction}

It is known that $\mathrm{Zn}-\mathrm{Al}$ alloys have good mechanical and tribological properties and therefore they have been used in many engineering applications. Zn-30Al (wt.\%) alloys exhibit high specific strength, excellent wear resistance, good casting properties and lower coat, making it a bearing alloy as a replacement of their conventional counterparts like cast iron and other nonferrous metals [1]. The addition of $\mathrm{Cu}$ to the eutectoid $\mathrm{Zn}-\mathrm{Al}$ alloys improves its mechanical properties, creep resistance and corrosion behavior [2,3]. $\mathrm{Zn}-\mathrm{Al}$ alloy containing small amounts of $\mathrm{Cu}$ has become of commercial importance as bearing materials [4].

Cooling rate is proved to be one of the effective parameters for controlling the microstructure of the alloys [5]. Both rapid solidification and slow cooling are involved in the whole metallurgical procedure. It has been recognized generally that the spray deposited process is an innovative technique of rapid solidification. In this process, droplets are first atomized from a molten metal stream, quickly cooled by an inert gas, then deposited on a substrate, and finally built up to form a low-porosity deposit with the required shape [6,7].

In this work, the ternary $\mathrm{Zn}-\mathrm{Al}-\mathrm{Cu}$ alloy was produced by the spray atomization and deposition technique. The objective of this study is to investigate the microstructural evolution and wear behavior of spray-deposited $\mathrm{Zn}-30 \mathrm{Al}-1 \mathrm{Cu}$ alloy.

\section{Experimental Procedures}

The nominal composition of the alloy was: $30 \% \mathrm{Al}, 1 \% \mathrm{Cu}$ (wt.\%) and balance zinc. The spray deposition experiment was conducted in an environmental chamber. During spray deposition process, the molten metal was atomized by $\mathrm{N}_{2}$ at $700{ }^{\circ} \mathrm{C}$, the distance of atomizing deposition was kept constant at $500 \mathrm{~mm}$. The microstructures of the alloys were characterized using optical microscopy $(\mathrm{OM})$, scanning electron microscopy (SEM) and X-ray diffraction (XRD). The macrographs of the alloys were carried out using an Axiocert 200MAT type optical microscope. A S360 type scanning electron microscopy working at $15 \mathrm{kV}$ was used to observe the microstructures and worn surfaces. The scanning electron microscopy samples were prepared using standard metallographic techniques and were etched using Keller's reagent. The X-ray diffraction experiments were performed on a Japan 
Rigaku diffractormeter using $\mathrm{Cu}-\mathrm{K} \alpha$ radiation. Wear tests were carried out using a pin-on-disc machine. The pin specimens were machined in the form of cylinders with $8 \mathrm{~mm}$ diameter and 12.7 $\mathrm{mm}$ length. The counterpart discs were made of a quenched and tempered T8 tool steel with a nominal chemical composition (mass \%): $\mathrm{Fe}-0.8 \% \mathrm{C}-0.35 \% \mathrm{Mn}-0.3 \% \mathrm{Si}$, surface hardness of $64 \mathrm{HRC}$ and surface roughness of $R \mathrm{a}=1 \mathrm{~m}$. The applied load was varied from 20 to $80 \mathrm{~N}(20,40,60$ and $80 \mathrm{~N})$. Sliding speed and distance were kept constant at $0.48 \mathrm{~m} / \mathrm{s}$ and $1.7 \mathrm{~km}$. The weight loss during wear test was measured using a photoelectric balance with the resolution of $\pm 0.1 \mathrm{mg}$. Three pins were used during each test. The specimens were thoroughly cleaned with acetone in ultrasonic cleaner before and after the wear test. Wear rate was calculated by dividing weight loss by sliding distance.

\section{Results and Discussion}

\section{Microstructure}

Fig. 1 shows optical micrographs of cast and spray-deposited $\mathrm{Zn}-30 \mathrm{Al}-1 \mathrm{Cu}$ alloy for comparison. It can be seen that the optical microscopy microstructure of cast alloy is composed of a typical dendritic microstructure of $\alpha$-Al matrix and interdendritic $\eta$-Zn secondary phases, in Fig. 1(a). The presence of dendritic microstructure was attributed to the low cooling rate, associated with the conventional solidification processes. Fig. 1(b) shows optical micrograph of the spray-deposited $\mathrm{Zn}-30 \mathrm{Al}-1 \mathrm{Cu}$ alloy, which is mainly composed of the lamella eutectoid phases. The equiaxed grains are about $20 \mu \mathrm{m}$ in size. The presence of the equiaxed grain morphology was attributed to the high cooling rate, associated with the rapid solidification processes.

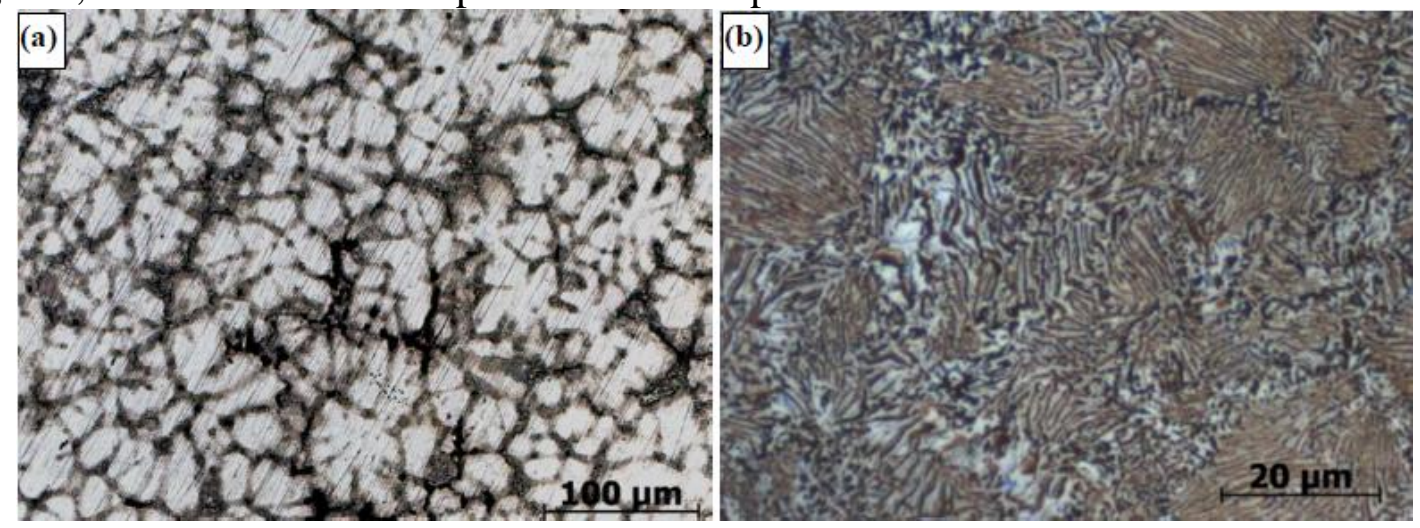

Fig. $1 \mathrm{OM}$ micrographs of the Zn-30Al-1Cu alloys, (a) as-cast; (b) as-deposited

SEM micrographs of as-cast Zn-30Al-1Cu alloy, Fig. 2(a) and (b), revealed some irregular compounds both on the grain boundaries and in the grain interiors. Energy dispersive X-ray analysis showed that the compounds contain $\mathrm{Cu}$ and $\mathrm{Zn}$ elements. Fig. 2(c) shows the micrograph of the spray deposited $\mathrm{Zn}-30 \mathrm{Al}-1 \mathrm{Cu}$ alloy, it was found that the lamellar structure eutectoid was primary phase in the microstructure of the alloy, and the presence of some compounds in the conventional cast $\mathrm{Zn}-30 \mathrm{Al}-1 \mathrm{Cu}$ alloy was suppressed.
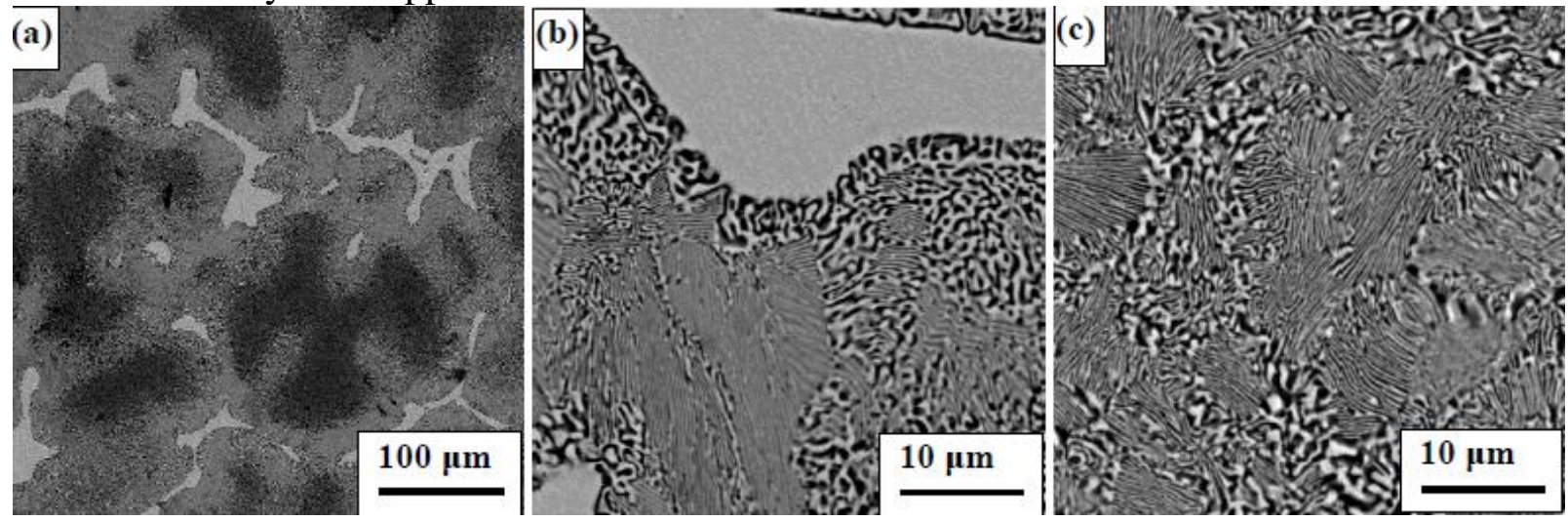

Fig. 2 SEM micrographs of Zn-30Al-1Cu alloy, (a),(b) as-cast, (c) as-deposited 
Fig. 3 shows the X-ray diffraction (XRD) patterns of the cast and spray-deposited $\mathrm{Zn}-30 \mathrm{Al}-1 \mathrm{Cu}$ alloys. XRD was performed to identify the phases in the microstructures, and analysis of the diffraction patterns shows that the compound phases mainly are $\varepsilon-\mathrm{CuZn}_{4}$ in the cast alloy. No definitive evidence for the presence of $\varepsilon-\mathrm{CuZn}_{4}$ was found in the XRD result of spray-deposited alloy.

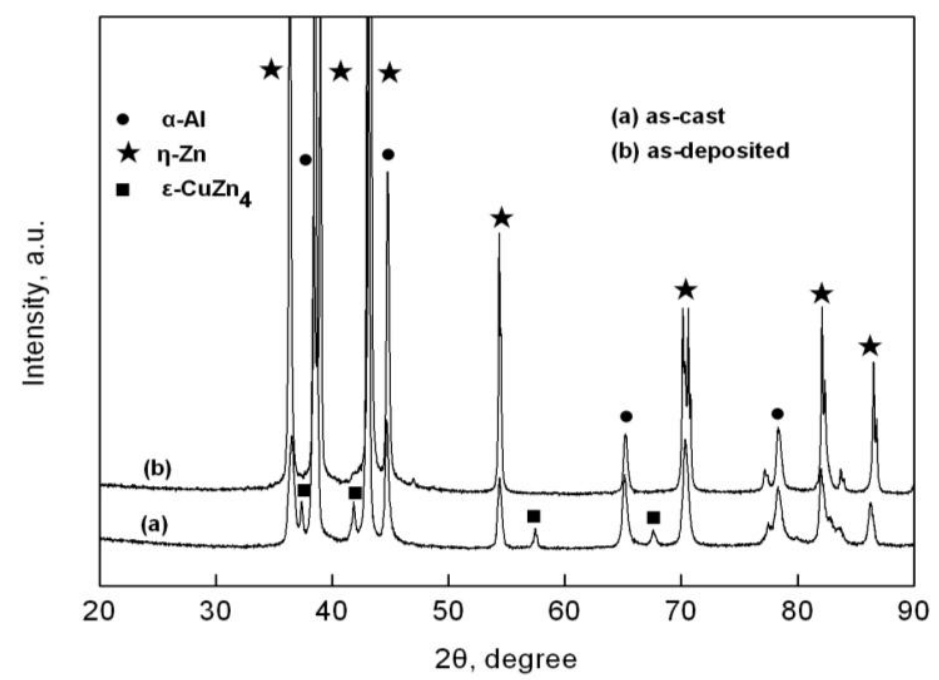

Fig. $3 \mathrm{X}$-ray diffraction patterns of the cast and spray-deposited $\mathrm{Zn}-30 \mathrm{Al}-1 \mathrm{Cu}$ alloys, (a) as-cast; (b) as-deposited

\section{Wear Tests}

Fig. 4 shows the effect of applied load on the wear rates of the conventional casting and spray-deposited $\mathrm{Zn}-30 \mathrm{Al}-1 \mathrm{Cu}$ alloys in the load range of 20-80 N. Obviously, the wear rate of the alloys increases with increasing load. In the entire applied load range, the spray-deposited alloy shows better wear resistance than the conventional casting alloy. Inspection of the results shown in Fig. 4 suggests that the wear resistance of spray-deposited $\mathrm{Zn}-30 \mathrm{Al}-1 \mathrm{Cu}$ alloy is better than that of the conventional casting one. Fig. 5 shows typical worn surfaces of the pins at the applied load of $80 \mathrm{~N}$. From Fig. 5(a), some large dimples can be seen on the worn surface of the conventional casting $\mathrm{Zn}-30 \mathrm{Al}-1 \mathrm{Cu}$ alloy, it indicates that the $\varepsilon-\mathrm{CuZn} 4$ compounds with irregular shapes were fractured and broken off during wear. In this case, no material transfer from pin to disc occurred during wear test. The grooves are very fine, and few small dimples can be observed on the worn surface of spray-deposited alloy, as shown in Fig. 5(b).

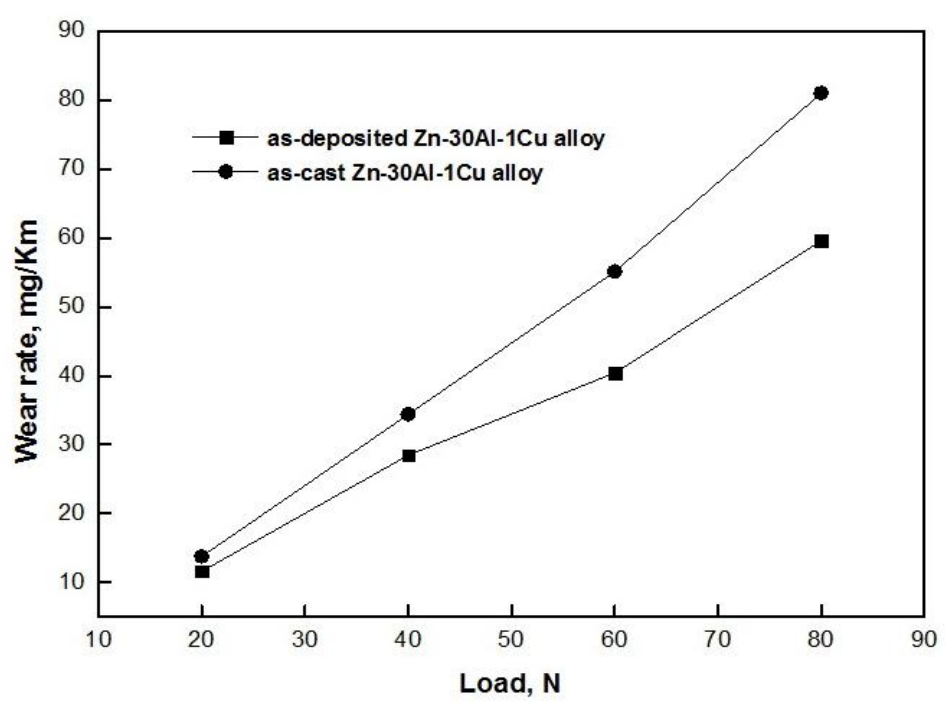

Fig. 4 Variations in the wear rates of as-cast and as-spray-deposited $\mathrm{Zn}-30 \mathrm{Al}-1 \mathrm{Cu}$ alloys with load 

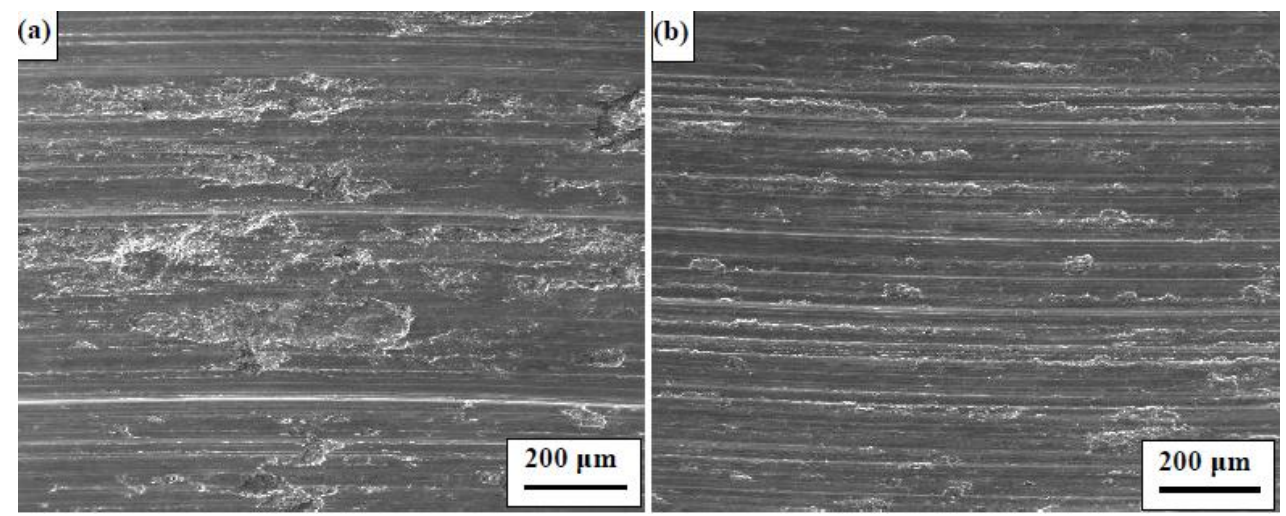

Fig. 5 SEM morphologies of worn surfaces of Zn-30Al-1Cu alloys at the load of $80 \mathrm{~N}$ : (a) as-cast; (b) as-deposited.

The wear rate and worn surface exhibited different characteristics for the cast and spray deposited $\mathrm{Zn}-30 \mathrm{Al}-1 \mathrm{Cu}$ alloy. One of the important parameters which greatly affect the wear property of the $\mathrm{Zn}-30 \mathrm{Al}-1 \mathrm{Cu}$ alloys is the $\varepsilon-\mathrm{CuZn}_{4}$ compounds with irregular shapes in the matrix. However, the $\varepsilon-\mathrm{CuZn}_{4}$ phase was found to have significant influences on the wear behavior. During wear tests, extensive fracture of $\varepsilon-\mathrm{CuZn} \mathrm{Z}_{4}$ compounds occurred, and the $\varepsilon-\mathrm{CuZn}_{4}$ compounds appeared to fracture more frequently than lamellar structure $\alpha-\mathrm{Al}+\eta$ - Zn eutectoid. With increasing load, the $\varepsilon-\mathrm{CuZn}_{4}$ compounds fracture above a certain load, and the fragmented of the $\varepsilon-\mathrm{CuZn}_{4}$ compounds lose their ability to support the load. In this case, the $\alpha-\mathrm{Al}+\eta$-Zn eutectoid matrix becomes in direct contact with the counterfaces. The broken, hard $\varepsilon-\mathrm{CuZn}_{4}$ compounds entrapped between the counterface and the alloys may act as third-body abraders and be responsible for the production longitudinal grooves on the worn surfaces, as can be seen in Fig. 5. The fractured $\varepsilon-\mathrm{CuZn} \mathrm{n}_{4}$ compounds promote the worn surface damage and act as third-body abrasives, thus, the spray-deposited $\mathrm{Zn}-30 \mathrm{Al}-1 \mathrm{Cu}$ alloy provided better wear resistance than the cast one.

\section{Summary}

The microstructure of spray-deposited $\mathrm{Zn}-30 \mathrm{Al}-1 \mathrm{Cu}$ alloy is mainly composed of the $\mathrm{Zn} / \mathrm{Al}$ eutectoids, and the presence of $\varepsilon-\mathrm{CuZn}_{4}$ compounds in the conventional cast alloy was suppressed. The spray-deposited $\mathrm{Zn}-30 \mathrm{Al}-1 \mathrm{Cu}$ alloy provides better wear resistance compared to the conventional cast one.

\section{Acknowledgements}

This work was supported by the National Natural Science Foundation of China (No. 51271037).

\section{References}

[1] M. Aydin and T. Savaskan: Inter. J. Fatigue Vol. 26(2004), p. 103.

[2] H. J. Dorantes-Rosales, V. M. Lopez-Hirata, J. L. Mendez-Velazquez, M. L. Saucedo-Munoz and D. Hernandez-Silva: J. Alloys Compd. Vol. 313(2000), p.154.

[3] R. Mojaver and H. R. Shahverdi: Wear. Vol. 271(2011), p. 2899.

[4] B. Bobic, J. Bajet, Z. Acimovic-Pavlovic, M. Rakin and I. Bobic: Corros. Sci. Vol. 53(2011) p. 409.

[5] R. Mojawer and H.R. Shahverdi: Wear. Vol. 268(2010), p. 605.

[6] P. Bai, X. Hou, X. Zhang, C. Zhao and Y. Xing: Mater. Sci. Eng., A Vol. 508 (2009), p. 23.

[7] M. M. Sharma, M. F. Amateau and T. J. Eden: Acta Mater. Vol. 53(2005), p. 2919. 